\title{
Tuning the aspect ratio of arrays of silica nanochannels
}

Nicola Zucchetto and Dominik Brühwiler*

Institute of Chemistry and Biological Chemistry

Zürich University of Applied Sciences

CH-8820 Wädenswil, Switzerland

* Corresponding author: dominik.bruehwiler@zhaw.ch

RSC Advances 5 (2015) 74638 - 74644. 


\section{Abstract}

Arrays of silica nanochannels (ASNCS) are ordered mesoporous silica particles with hexagonal prismatic shape. The entrances of the well-defined one-dimensional nanochannels are located on the base surfaces of the hexagonal prisms. The aspect ratio of the micrometer-sized particles (length-to-diameter ratio) can be tuned in the range of 0.8 to 2.2 by the addition of co-ions $\left(\mathrm{K}^{+}\right.$and $\left.\mathrm{Ca}^{2+}\right)$ to the hexadecyltrimethylammonium bromide (CTAB) templated synthesis and by an adjustment of the relative amounts of silica precursor (tetraethoxysilane) and CTAB. The length of the nanochannels can be varied between 2 and $9 \mu \mathrm{m}$. Co-ions thereby not only improve the regularity of the hexagonal prismatic particle shape, but also affect the diameter of the nanochannels, which lies at approximately $2.6 \mathrm{~nm}$ (with $\mathrm{K}^{+}$as co-ion) and $3.2 \mathrm{~nm}$ (with $\mathrm{Ca}^{2+}$ as co-ion). 


\section{Introduction}

Ordered mesoporous silica materials provide a versatile platform for the development of a variety of applications, including diverse fields such as sensor technology, ${ }^{1-4}$ drug delivery, ${ }^{5-8}$ catalysis, ${ }^{9-11}$ imaging, ${ }^{12,13}$ and light-harvesting. ${ }^{14,15}$ As the different applications require specific particle sizes and shapes, methods to control the growth of the mesoporous silica particles have become increasingly important. Examples include the synthesis of mesoporous silica nanoparticles by growth suppression in the presence of co-surfactants such as Pluronic $\mathrm{F} 127,{ }^{16}$ morphology control by co-condensation of organoalkoxysilanes, ${ }^{17}$ or size control with co-solvents. ${ }^{18}$

Arrays of Silica Nanochannels (ASNCs) are an exceptional mesoporous material due to the well-defined hexagonal prismatic particle shape and the one-dimensional channel system with entrances located on the opposing base surfaces (Fig. 1). ${ }^{19-24}$ ASNCs can thus be considered as the mesoporous analogue to hexagonal zeolites with one-dimensional channel systems that have for example been used as host materials for the supramolecular organization of guest molecules. ${ }^{25,26}$ With their larger pore size, ASNCs extend the possibilities of the zeolite-based host-guest concept by allowing the introduction of guest species that are larger than the pore size range covered by zeolites. In terms of surface properties, ASNCs are similar to the well-known MCM-41 type materials, which are characterized by noninterconnected channels, but generally do not feature a defined particle shape. In analogy to MCM-41, ASNCs possess abundant silanol groups that allow for surface functionalization. ${ }^{21,22}$

The morphogenesis of mesoporous silica fibers was first proposed by Ozin and co-workers. ${ }^{27}$ Liquidcrystal embryos with hexagonal cross-sections start the growth after the silane addition. The final shape of the particles depends on the reaction conditions. It has been observed that $\mathrm{pH}$, dielectric constant, and ionic strength influence the starting shape and subsequent growth. In highly acidic solutions, end-on growth is promoted, leading to the formation of fibers with hexagonal cross-section. Side-on growth becomes more favourable at higher $\mathrm{pH}$. Classical ASNCs, as originally reported by Kievsky and Sokolov, ${ }^{19}$ 
are a few micrometers long with a large aspect ratio (length/diameter). The synthesis is conducted at low $\mathrm{pH}$ with hexadecyltrimethylammonium chloride (CTAC) as a structure-directing agent. The growth of the ASNCs is driven by the formation of mesoporous intermediates of the type $\mathrm{S}^{+} \mathrm{X}^{-} \mathrm{I}^{+}$, containing the cationic surfactant $\left(\mathrm{S}^{+}\right)$, the counter-ion $\left(\mathrm{X}^{-} ; \mathrm{Cl}^{-}\right.$in the case of $\left.\mathrm{CTAC}\right)$, and protonated silicate species $\left(\mathrm{I}^{+}\right)$.

Control of the length, diameter, and aspect ratio of ASNCs is desirable, as it would open possibilities for tailor-made host materials, e.g. with adaptable nanochannel length. Low aspect ratios (disc-shaped particles) are of particular interest due to the potential alignment of such particles on a substrate, leading to a perpendicular orientation of the nanochannels. Organized particle assemblies of this kind have been obtained with microporous materials such as zeolite $L .{ }^{28-33}$ The variety of zeolite $L$ particle assemblies reported in the literature can be ascribed to the tunable size and aspect ratio of zeolite $\mathrm{L}$ crystals, $^{34,35}$ as well as to sophisticated methods for the selective functionalization of the channel entrances. ${ }^{36-39}$ Methods for the selective functionalization of the external surface and of the pore surface of ASNCs that also enable the placement of functional groups at the pore entrances have been reported, ${ }^{21,22}$ but concepts for the adjustment of the particle size and aspect ratio have not been developed.

The objective of this work was to identify parameters in the synthesis of ASNCs that influence the aspect ratio of ASNCs, while retaining a narrow pore size distribution and a well-defined hexagonal prismatic particle shape. Experiments with the addition of $\mathrm{KCl}$ or $\mathrm{CaCl}_{2}$ revealed a considerable effect of the co-ions on the ASNCs particle dimensions, as well as on the pore size. Adjustment of the silane/surfactant ratio allows for tuning of the aspect ratio and of the nanochannel length over a wide range. The ability to adjust the length of well-defined nanochannels is considered relevant for the investigation of transport processes in nanoscale geometries. ${ }^{24}$ 

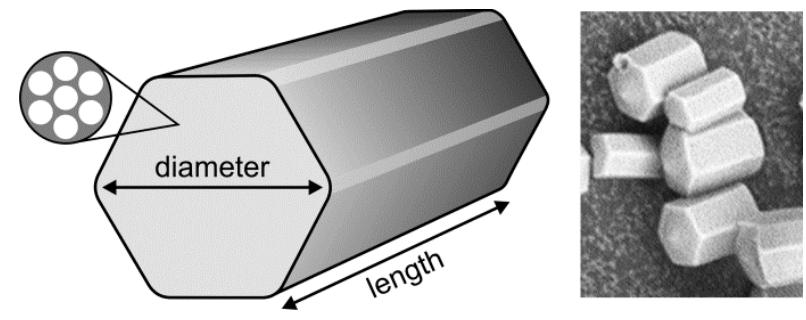

Fig. 1. Schematic illustration of an ASNCs particle. The aspect ratio corresponds to the length-todiameter ratio. The SEM image on the right shows the regular hexagonal prismatic shape of ASNCs. In this image, the length of the particles is approximately $4 \mu \mathrm{m}$.

\section{Experimental section}

Materials. Hexadecyltrimethylammonium bromide (CTAB, $96 \%), \mathrm{KCl}(\geq 99.0 \%), \mathrm{CaCl}_{2}(\geq 97.0 \%)$, concentrated hydrochloric acid (puriss p.a., $\geq 32 \%$ ), and tetraethoxysilane (TEOS, 99.999\%) were obtained from Sigma Aldrich. Hexadecyltrimethylammonium chloride (CTAC, $99 \%$ ) was obtained from Acros. All chemicals were used as received.

Synthesis of ASNCs. ASNCs were synthesized by the classical route (with CTAC) following a previously published procedure. ${ }^{21}$ For a typical alternative synthesis with CTAB instead of CTAC, CTAB (4.0 g, $11 \mathrm{mmol}$ ) was dissolved in a mixture of doubly distilled $\mathrm{H}_{2} \mathrm{O}(76 \mathrm{~mL}, 4.2 \mathrm{~mol})$ and concentrated hydrochloric acid ( $\geq 32 \%, 60 \mathrm{~mL}, 0.62 \mathrm{~mol}$ ) by stirring for $15 \mathrm{~min}$ in a polypropylene beaker. The solution was subsequently cooled to $0{ }^{\circ} \mathrm{C}$ in an ice bath for $15 \mathrm{~min}$ under quiescent conditions, followed by the slow addition of cold TEOS $\left(4{ }^{\circ} \mathrm{C}, 2.0 \mathrm{~mL}, 9 \mathrm{mmol}\right)$ and further stirring for $30 \mathrm{~s}$. The resulting mixture was kept at $0{ }^{\circ} \mathrm{C}$ under quiescent conditions for $4 \mathrm{~h}$. The product was collected by filtration and washed with $\mathrm{H}_{2} \mathrm{O}(250 \mathrm{~mL})$. Additional syntheses were conducted with the addition of $\mathrm{KCl}$ and $\mathrm{CaCl}_{2}$. An amount of $3.36 \mathrm{~g}(45 \mathrm{mmol})$ of $\mathrm{KCl}$ or $1.50 \mathrm{~g}(13.5 \mathrm{mmol})$ of $\mathrm{CaCl}_{2}$ was found to give the best products in terms of regular hexagonal prismatic particle morphology. 
Syntheses with different TEOS/CTAB ratios were performed by the above procedure using a constant amount of CTAB and changing the amount of TEOS. After the dissolution of $\mathrm{CTAB}$ and $\mathrm{CaCl}_{2}$ (stirring for $15 \mathrm{~min})$, the solution was cooled in an ice bath for $30 \mathrm{~min}$ under quiescent conditions and the respective amount of cold TEOS was added under stirring (for $30 \mathrm{~s}$ ). The mixture was left at $0{ }^{\circ} \mathrm{C}$ for at least 90 min under quiescent conditions.

For all materials, the structure-directing agent was removed by first heating at $300{ }^{\circ} \mathrm{C}$ for $2 \mathrm{~h}$ and subsequent calcination in air at $550^{\circ} \mathrm{C}$ for $12 \mathrm{~h}$. Heating rates of $2^{\circ} \mathrm{C} / \mathrm{min}$ were applied.

Characterization. Scanning electron microscopy (SEM) images were obtained with a FEI PHENOM-Pro. Particle size distributions were determined from the SEM images with ImageJ (version 1.48s, National Institutes of Health, USA). For each sample, 90 particles from three different syntheses were measured (270 particles in total) to obtain length, diameter, and aspect ratio (length/diameter). Powder X-ray diffraction (XRD) patterns were recorded on a STOE STADI P diffractometer in transmission mode (Ge monochromator) with $\mathrm{CuKa}_{1}$ radiation. Nitrogen sorption isotherms were measured at $77 \mathrm{~K}$ with a Quantachrome Autosorb iQ MP. Pore size distributions and average pore diameters $\left(d_{\mathrm{DFT}}\right)$ were determined by a nonlocal density functional theory (NLDFT) model developed for silica exhibiting cylindrical pore geometry. ${ }^{40}$ Total pore volumes $\left(V_{\text {tot }}\right)$ were calculated at a relative pressure $\mathrm{p} / \mathrm{p}_{0}$ of 0.95 . Primary mesopore volumes $\left(V_{\mathrm{p}}\right)$ were determined from the respective $\alpha_{\mathrm{s}}$-plots. ${ }^{41}$ Adsorption isotherms were used for all calculations. ${ }^{42}$

\section{Results and discussion}

Effect of counter-ions on particle morphology. Time and temperature play an essential role in the synthesis of ASNCs. Further parameters to be considered are the composition and the surfactantsolution interactions. While the surfactant is dissolving, before the addition of TEOS, the formation of 
micelles is observed, leading to the appearance of long micellar rods. The quiescent period at low temperature is a fundamental step, as the system energy decreases and micellar interactions are established. Upon addition of TEOS, silica growth from seeds to rods starts, driven by the formation of mesoporous intermediates $\mathrm{S}^{+} \mathrm{X}^{-} \mathrm{I}^{+}$. In the classical synthesis of ASNCs using $\mathrm{CTAC}$, only $\mathrm{Cl}^{-}$is present as counter-ion and the yield in terms of a regular hexagonal prismatic shape is high. When replacing CTAC with the more common $\mathrm{CTAB}, \mathrm{Br}^{-}$is introduced as an additional counter-ion. This has a noticeable effect on the particle size and morphology (Fig. 2), despite the fact that the concentration of $\mathrm{Br}^{-}$is about 56 times less than the concentration of $\mathrm{Cl}^{-}$, due to the hydrochloric acid present in the reaction mixture. The observation of an apparently strong interaction between $\mathrm{Br}^{-}$and micelles is in agreement with previous studies that have shown that $\mathrm{Cl}^{-}$is inefficient at replacing $\mathrm{Br}^{-}$from CTAB micelles. ${ }^{43}$ The synthesis with CTAB yields a large fraction of deformed hexagonal particles. Considering the placement of $\mathrm{Cl}^{-}$and $\mathrm{Br}^{-}$in the anionic lyotropic series observed for $\mathrm{CTAB},{ }^{44}$ we can expect that $\mathrm{Br}^{-}$is more effective at reducing micellar charge, thus causing the formation of long rod-shaped micelles, ultimately leading to the generation of fiber-shaped silica particles. ${ }^{45}$ It should be noted that conducting the synthesis with $\mathrm{HBr}$ instead of $\mathrm{HCl}$ does not yield ASNCs.

Effect of co-ions on particle morphology. Unlike the counter-ions, co-ions have the same charge as the surfactant molecules. The effect of co-ions on the micelles is therefore expected to be less pronounced. However, we have observed a distinct influence of the co-ions on the ASNCs particle size and porosity. The product quality of the CTAB synthesis in terms of a uniform particle size and shape can be considerably improved by the addition of $\mathrm{KCl}$ or $\mathrm{CaCl}_{2}$. In these syntheses, the $\mathrm{Cl}^{-} / \mathrm{Br}^{-}$ratio is only slightly increased compared to the pathway without salt addition (from 56 to a maximum of 60 ). ASNCs prepared with $\mathrm{CTAB} / \mathrm{KCl}$ feature an average length similar to the particles obtained with the classical CTAC synthesis ( 4.7 and $4.8 \mu \mathrm{m}$, respectively). Shorter particles are obtained when using $\mathrm{CTAB} / \mathrm{CaCl}_{2}$ $(4.1 \mu \mathrm{m})$. In both cases, $\mathrm{CTAB} / \mathrm{KCl}$ and $\mathrm{CTAB} / \mathrm{CaCl}_{2}$, particles with increased diameter $(2.6$ and $2.9 \mu \mathrm{m}$, 
respectively) are obtained compared to the classical CTAC pathway $(2.0 \mu \mathrm{m})$. As a consequence, the aspect ratio decreases from $2.4(\mathrm{CTAC})$ to $1.8(\mathrm{CTAB} / \mathrm{KCl})$ and $1.4\left(\mathrm{CTAB} / \mathrm{CaCl}_{2}\right)$. The particle dimensions are summarized in Tab. 1 and representative SEM images are shown in Fig. 2.
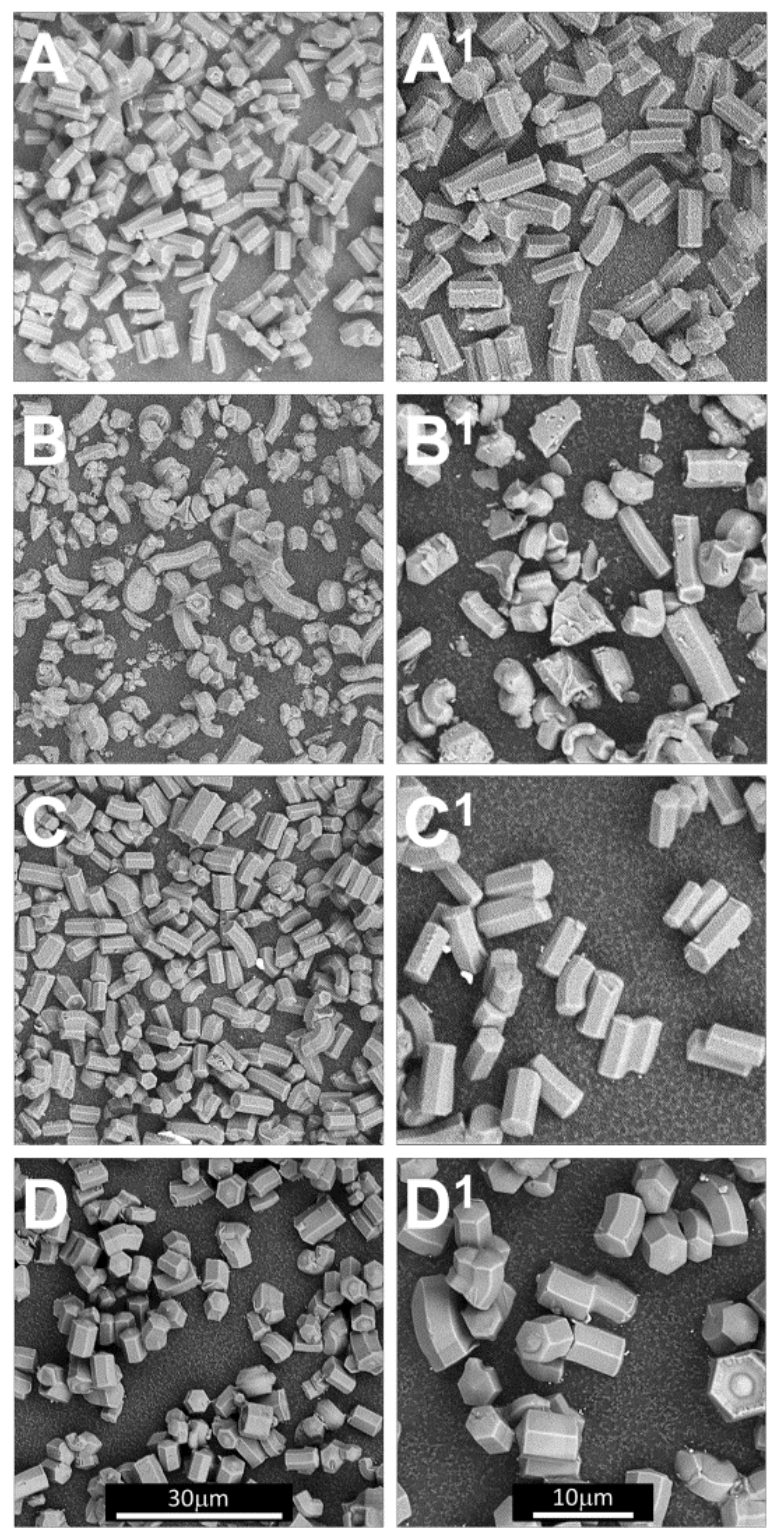

Fig. 2. $S E M$ images of $A S N C$ s synthesized with $\operatorname{CTAC}\left(A / A^{1}\right), C T A B\left(B / B^{1}\right), C T A B / K C l\left(C / C^{1}\right)$, and $C T A B / C a C l$, $\left(D / D^{1}\right)$. 
Table 1. ASNCs particle dimensions.

\begin{tabular}{lccc}
\hline & length $/ \mu \mathrm{m}$ & diameter $/ \mu \mathrm{m}$ & aspect ratio \\
\hline $\mathrm{CTAC}$ & $4.8 \pm 0.5$ & $2.0 \pm 0.3$ & $2.4 \pm 0.4$ \\
$\mathrm{CTAB} / \mathrm{KCl}$ & $4.7 \pm 0.4$ & $2.6 \pm 0.4$ & $1.8 \pm 0.3$ \\
$\mathrm{CTAB} / \mathrm{CaCl}_{2}$ & $4.1 \pm 0.4$ & $2.9 \pm 0.4$ & $1.4 \pm 0.3$ \\
\hline
\end{tabular}

Effect of co-ions on porosity. Nitrogen sorption isotherms and the corresponding pore size distributions of ASNCs synthesized with $\mathrm{CTAB}, \mathrm{CTAB} / \mathrm{KCl}$ or $\mathrm{CTAB} / \mathrm{CaCl}_{2}$ are presented in Fig. 3. Similar to ASNCs synthesized with CTAC, ASNCs templated by $\mathrm{CTAB}$ with $\mathrm{KCl}$ or $\mathrm{CaCl}_{2}$ feature reversible pore condensation at $\mathrm{p} / \mathrm{p}_{0}<0.4$, as expected for ordered mesoporous materials with pore diameters below $4 \mathrm{~nm}^{.46}$ Comparison of the total pore volume $\left(V_{\text {tot }}\right)$ to the primary mesopore volume $\left(V_{\mathrm{p}}\right)$ indicates that the contribution of secondary mesopores is small in all investigated materials (Tab. 2). Interestingly, the presence of $\mathrm{K}^{+}$in the synthesis mixture leads to a reduced pore diameter $\left(d_{\mathrm{DFT}}\right)$ when compared to the samples prepared with CTAC or CTAB only, whereas $\mathrm{Ca}^{2+}$ has the opposite effect. While the influence of the counter-ion on the aggregation behaviour of surfactants is generally well understood and can be interpreted in terms of polarizability and hydration, the role of co-ions is less clear. ${ }^{43,44}$ Previous studies indicate that co-ions have only a minor effect on the sphere-rod transition, but that the sizes of rodlike micelles can differ considerably depending on the type of co-ion. ${ }^{47,48} \mathrm{~A}$ comparison of $\mathrm{CTAB} / \mathrm{KCl}$ and $\mathrm{CTAB} / \mathrm{NaCl}$ systems revealed that $\mathrm{K}^{+}$had a more pronounced effect on the micelles, which was attributed to the larger extent of penetration of $\mathrm{K}^{+}$into the micellar corona. ${ }^{47}$ In the lyotropic series observed for cations with $\mathrm{CTAB}, \mathrm{Ca}^{2+}$ is placed much higher than $\mathrm{K}^{+}$, as expected from the charge and hydrated radius. ${ }^{44}$ The investigation of the effect of co-ions on sodium dodecyl sulfate (SDS) micelles showed that the molecular mass of the rod-like micelles changes in the order of the lyotropic series of the co-ions. The difference in micelle size was attributed to the effect of co-ions on the hydrophobic interaction in 
the micelle formation and to the alteration of the hydrogen-bonded structure of water. ${ }^{48}$ We can therefore expect an increase of micelle size when using $\mathrm{Ca}^{2+}$ instead of $\mathrm{K}^{+}$in combination with CTAB.
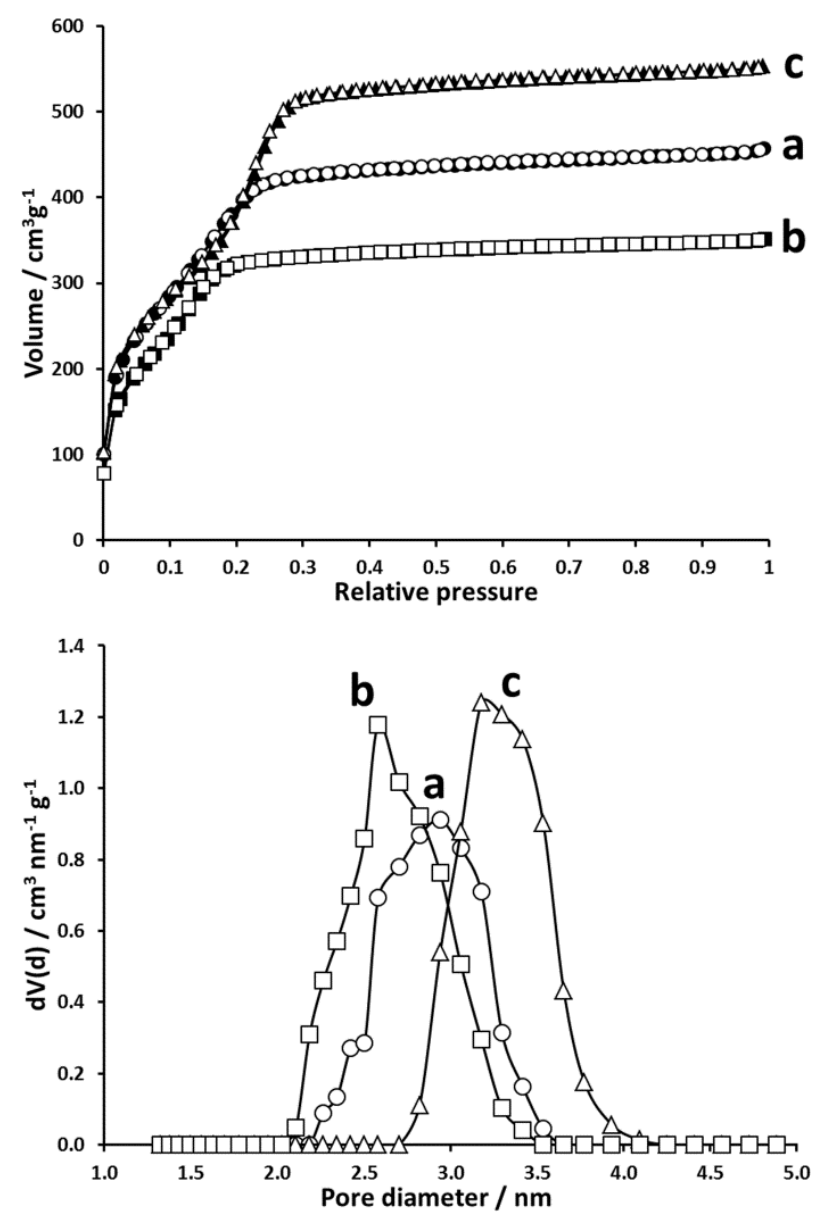

Fig. 3. Top: Nitrogen adsorption (open symbols) and desorption (filled symbols) isotherms of ASNCs synthesized with $\mathrm{CTAB}(\mathrm{a}), \mathrm{CTAB} / \mathrm{KCl}(\mathrm{b})$, and $\mathrm{CTAB} / \mathrm{CaCl}_{2}$ (c). Bottom: Respective pore size distributions. 
Table 2. Nitrogen adsorption data.

\begin{tabular}{lccc}
\hline & $V_{\text {tot }} / \mathrm{cm}^{3} \mathrm{~g}^{-1}$ & $V_{\mathrm{p}} / \mathrm{cm}^{3} \mathrm{~g}^{-1}$ & $d_{\mathrm{DFT}} / \mathrm{nm}$ \\
\hline $\mathrm{CTAC}$ & 0.60 & 0.56 & 2.94 \\
$\mathrm{CTAB}$ & 0.71 & 0.64 & 2.94 \\
$\mathrm{CTAB} / \mathrm{KCl}$ & 0.54 & 0.52 & 2.58 \\
$\mathrm{CTAB} / \mathrm{CaCl}_{2}$ & 0.86 & 0.78 & 3.18 \\
\hline
\end{tabular}

In order to obtain further information regarding the substantial differences between the samples prepared with $\mathrm{CTAB} / \mathrm{KCl}$ and $\mathrm{CTAB} / \mathrm{CaCl}_{2}$, we have conducted XRD measurements. Powder XRD patterns of the samples show three peaks that can be assigned to the (100), (110), and (200) reflexes of the 2D hexagonal space group p6mm (Fig. 4). This is a feature that is considered typical of well-ordered MCM-41 type materials. ${ }^{49}$ The repeat distance $a_{0}$ was calculated from the $d_{100}$ value according to eq. 1 . Assuming hexagonal base surfaces with an average diameter $D$ obtained from the SEM images, the number of channels per particle $N_{c}$ can be estimated by applying eq. 2 .

$a_{0}=\frac{2 d_{100}}{\sqrt{3}}$

$N_{c}=0.75\left(\frac{D}{a_{0}}\right)^{2}$

For structures that can be approximated as an infinite hexagonal array of cylindrical pores, the pore diameter can be calculated by a purely geometrical approach combining XRD and nitrogen adsorption data according to eq. $3 .^{50}$ The pore wall thickness $w_{\mathrm{XRD}}$ can then be calculated by subtraction of $d_{\mathrm{XRD}}$ from $a_{0}$. 


$$
d_{\mathrm{XRD}}=\sqrt{\frac{8}{\sqrt{3} \pi}} \cdot d_{100} \cdot \sqrt{\frac{\rho V_{\mathrm{p}}}{1+\rho V_{\mathrm{p}}}}
$$

A value of $\rho=2.2 \mathrm{~g} \mathrm{~cm}^{-3}$ is typically used for the density of the pore walls. This calculation is an alternative to the exclusively nitrogen sorption data based pore size analysis. The results of the calculations are summarized in Tab. 3. In agreement with the pore diameters obtained from the NLDFT analysis of the nitrogen adsorption isotherms (Tab. 2), the values calculated by the geometrical approach (eq. 3) support the observation that the $\mathrm{CTAB} / \mathrm{CaCl}_{2}$ system produces $\mathrm{ASNCs}$ with larger average pore diameter than the $\mathrm{CTAB} / \mathrm{KCl}$ system.

The larger particle diameter of the ASNCs synthesized with $\mathrm{CTAB} / \mathrm{CaCl}{ }_{2}$ can be interpreted as a direct consequence of the larger pore size, considering the comparable number of nanochannels per particle. It is interesting to note that the ASNCs made with the $\mathrm{CTAB} / \mathrm{CaCl}{ }_{2}$ system feature slightly thinner pore walls.

Table 3. Structural parameters derived from XRD and nitrogen adsorption data.

\begin{tabular}{lccccc}
\hline & $a_{0} / \mathrm{nm}$ & $d_{100} / \mathrm{nm}$ & $d_{\mathrm{XRD}} / \mathrm{nm}$ & $w_{\text {XRD }} / \mathrm{nm}$ & $N_{\mathrm{c}}$ \\
\hline $\mathrm{CTAB} / \mathrm{KCl}$ & 3.57 & 3.09 & 2.74 & 0.83 & $397^{\prime} 806$ \\
$\mathrm{CTAB} / \mathrm{CaCl}_{2}$ & 3.85 & 3.33 & 3.21 & 0.64 & $425^{\prime} 536$ \\
\hline
\end{tabular}




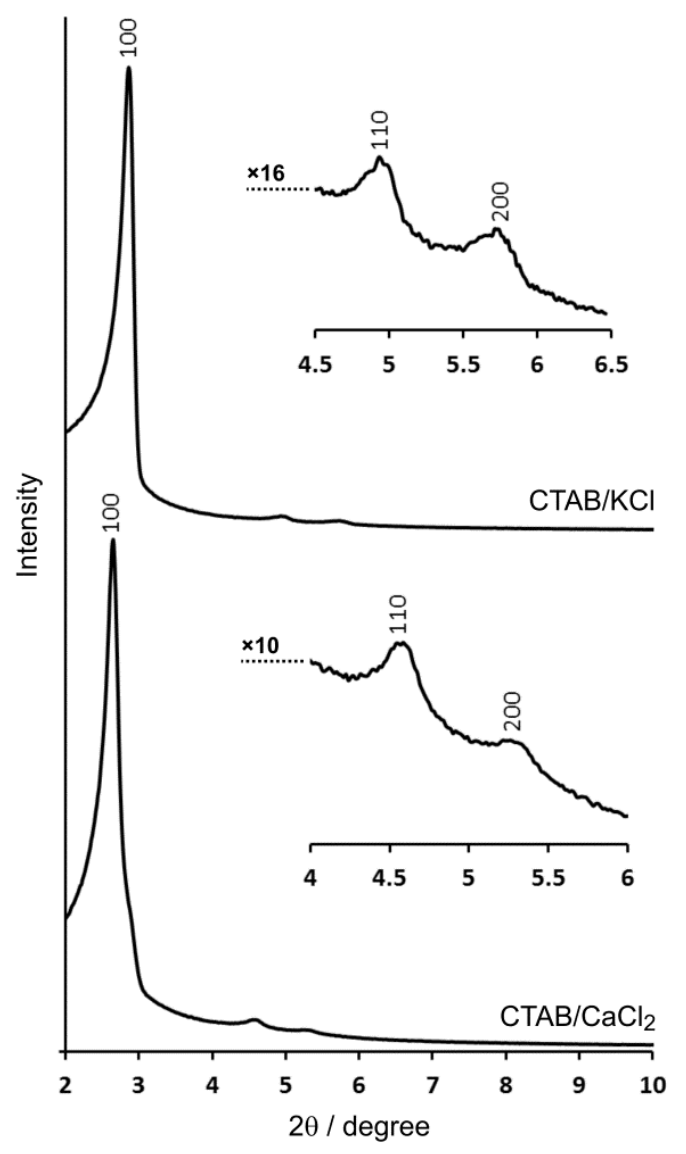

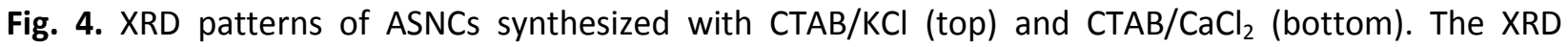
patterns are offset for clarity.

Adjustment of the nanochannel length and particle aspect ratio. The preparation of ASNCs with $\mathrm{CTAB} / \mathrm{CaCl}_{2}$ yields particles with slightly shorter nanochannels, compared to the products of the classical synthesis pathway using CTAC. At the same time, the aspect ratio of the particles is reduced from 2.4 to 1.4. By variation of the TEOS/CTAB ratio, the nanochannel length (corresponding to the particle length) and the aspect ratio can be adjusted over a wide range, as shown in Fig. 5 and 6 . The overall particle size (length and diameter) gradually increased with increasing amount of TEOS. As can be seen from Fig. 6, the amount of TEOS had a more pronounced effect on the particle length, indicating preferential end-on growth. No further length or diameter increase was observed at TEOS/CTAB $>1$. For small amounts of 
TEOS, the particle length became smaller than the diameter, resulting in an aspect ratio of 0.8 . Within the investigated TEOS/CTAB ratio range, no significant effect of the TEOS/CTAB ratio on the pore diameter of the resulting ASNCs was observed. This allows us to control the nanochannel length without affecting the nanochannel diameter.

Further reduction of the amount of TEOS (leading to a TEOS/CTAB ratio below 0.4 ) produced particles with partial hexagonal platelet-type shape but overall irregular morphology. It was generally observed that increasing the TEOS/CTAB ratio produces increasing amounts of curved ASNCs. This effect becomes noticeable only at TEOS/CTAB ratios larger than 0.8 .

Highly organized particle assemblies of zeolite $L$ with perpendicular nanochannel orientation relative to a substrate have been achieved due to the availability of zeolite L crystals with low aspect ratio and planar base surfaces. ${ }^{33}$ Concepts of selective channel entrance (base surface) functionalization have additionally allowed for the alignment of the zeolite $L$ crystals via favorable interactions between the base surfaces and the substrate. ${ }^{31}$ To achieve a similar degree of orientation with ASNCs, these requirements must be met. As can be seen from the SEM images (e.g. Fig. 6), the base surfaces of ASNCs are not always entirely planar, but show asperity due to end-on growth. Establishing favorable interactions between the base surfaces and the substrate is therefore considered essential; even more so if taking into account that at an aspect ratio of 0.8 , the lateral surfaces still contribute a larger area to the external particle surface area than the base surfaces. In an ideal case, the external particle surface of ASNCs is selectively functionalized to produce base surfaces that can covalently bind to a given substrate. Recent work on the control of functional group distributions on ASNCs can serve as a starting point for future work in this challenging field. ${ }^{21,22}$ 

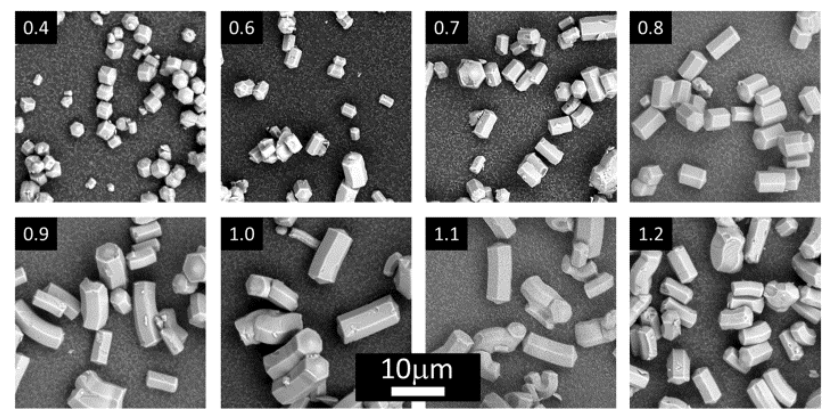

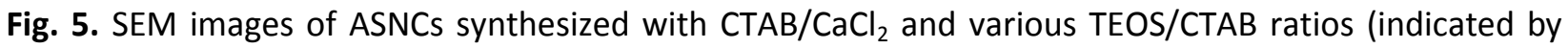
the number on the top left of each image).
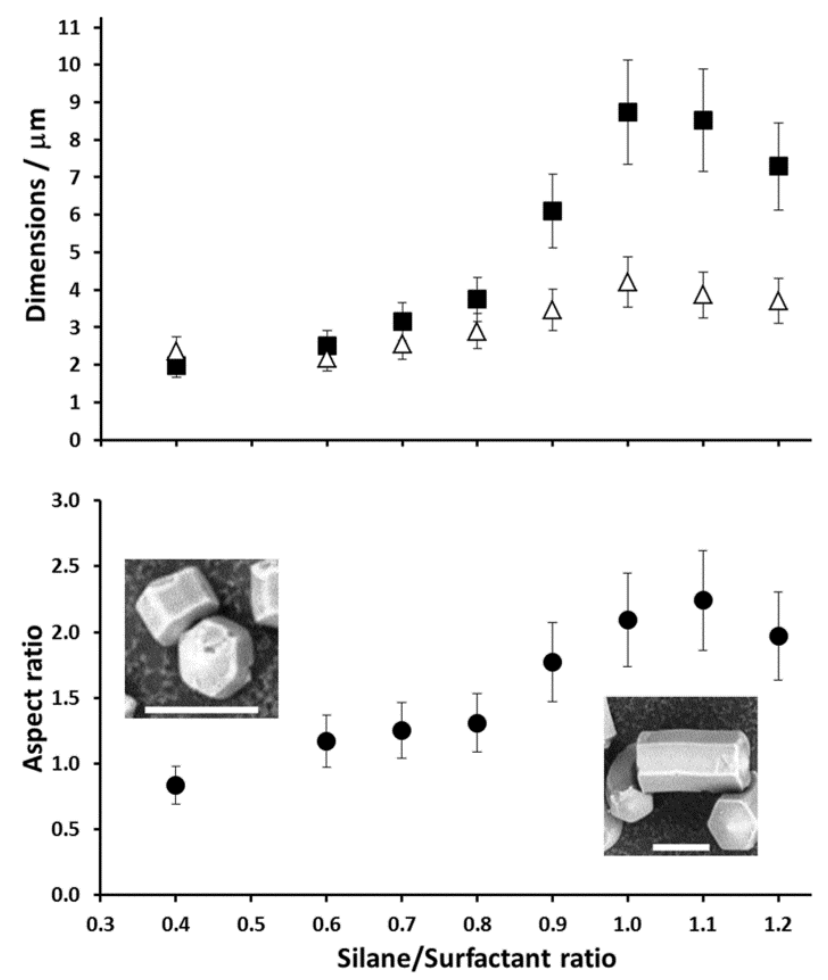

Fig. 6. Top: Length (squares) and diameter (triangles) of $A S N C s$ synthesized with $\mathrm{CTAB} / \mathrm{CaCl}$ in function of the silane/surfactant (TEOS/CTAB) ratio. Bottom: Respective aspect ratios. The SEM images correspond to samples prepared with a silane/surfactant ratio of 0.4 (left image) and 1.0 (right image). The scale bars are $5 \mu \mathrm{m}$. 


\section{Conclusions}

The use of $\mathrm{CTAB} / \mathrm{KCl}$ or $\mathrm{CTAB} / \mathrm{CaCl}_{2}$ in the synthesis of $A S N C$ s yields products that are comparable in terms of porosity and particle morphology to the products obtained by the classical pathway with CTAC as structure-directing agent. The combination of co-ions with CTAB thereby improves the yield of regular hexagonal prismatic particles. Interestingly, the co-ions also affect the pore diameter. Compared to the pathway without salt addition, the presence of $\mathrm{KCl}$ in the synthesis mixture leads to a reduced pore diameter, whereas $\mathrm{CaCl}_{2}$ has the opposite effect.

Adjusting the TEOS/CTAB ratio in the $\mathrm{CTAB} / \mathrm{CaCl}_{2}$ synthesis allows control of the length of the ASNCs and therefore of the nanochannel length. As the effect of the TEOS/CTAB ratio on the particle diameter is less pronounced, ASNCs of various aspect ratios can be prepared, with a minimum value of 0.8 . In analogy to microporous materials such as zeolite $\mathrm{L}^{33}$ low aspect ratio ASNCs might provide a solution for the generation of particle coatings, where the nanochannels are oriented perpendicular to the substrate. This so-called vertical nanochannel alignment has been at the centre of recent research efforts in the field of mesoporous silica thin films and is considered to be extremely challenging. ${ }^{51}$ Furthermore, the option to prepare ASNCs with various channel lengths will open new possibilities for the investigation of transport processes in porous media.

\section{Acknowledgements}

Financial support by the Swiss National Science Foundation (projects 140303 and 149715) is acknowledged. 


\section{References}

1 R. Gomes and A. Bhaumik, Microporous Mesoporous Mater., 2015, 207, 71-77.

2 H. Zhou, X. Lv, L. Zhang, A. Gong, A. Wu, Z. Liang, G. Peng and H. Lin, J. Mater. Chem. C, 2014, 2, 9625-9630.

3 E.-M. Seftel, P. Cool, A. Lloyd-Spetz and D. Lutic, C. R. Chimie, 2014, 17, 717-724.

4 B. J. Melde, B. J. Johnson and P. T. Charles, Sensors, 2008, 8, 5202-5228.

$5 \quad$ N. Z. Knežević and J.-O. Durand, Nanoscale, 2015, 7, 2199-2209.

6 S. Alberti, G. J. A. A. Soler-Illia and O. Azzaroni, Chem. Commun., 2015, 51, 6050-6075.

7 C. Coll, A. Bernardos, R. Martinez-Mañez and F. Sancenón, Acc. Chem. Res., 2013, 46, 339-349.

$8 \quad$ P. Yang, S. Gai and J. Lin, Chem. Soc. Rev., 2012, 41, 3679-3698.

9 T. Cheng, Q. Zhao, D. Zhang and G. Liu, Green Chem., 2015, 17, 2100-2122.

10 M. P. Conley, C. Copéret and C. Thieuleux, ACS Catal., 2014, 4, 1458-1469.

11 C. Yu and J. He, Chem. Commun., 2012, 48, 4933-4940.

12 H.-M. Meng, L. Lu, X.-H. Zhao, Z. Chen, Z. Zhao, C. Yang, X.-B. Zhang and W. Tan, Anal. Chem., 2015, 87, 4448-4454.

13 T. Maldiney, B. Ballet, M. Bessodes, D. Scherman and C. Richard, Nanoscale, 2014, 6, 13970-13976.

14 H. Takeda, M. Ohashi, Y. Goto, T. Ohsuna, T. Tani and S. Inagaki, Chem. Eur. J., 2014, 20, 9130-9136.

15 S. Inagaki, O. Ohtani, Y. Goto, K. Okamoto, M. Ikai, K. Yamanaka, T. Tani and T. Okada, Angew. Chem. Int. Ed., 2009, 48, 4042-4046.

16 K. Suzuki, K. Ikari and H. Imai, J. Am. Chem. Soc., 2004, 126, 462-463.

17 S. Huh, J. W. Wiench, B. G. Trewyn, S. Song, M. Pruski and V. S.-Y. Lin, Chem. Commun., 2003, 2364-2365.

18 Q. He, X. Cui, F. Cui, L. Guo and J. Shi, Microporous Mesoporous Mater., 2009, 117, 609-616.

19 Y. Kievsky and I. Sokolov, IEEE Trans. Nanotechnol., 2005, 4, 490-494.

20 D. O. Volkov, J. Benson, Y. Y. Kievsky and I. Sokolov, Phys. Chem. Chem. Phys., 2010, 12, 341-344.

21 N. Gartmann and D. Brühwiler, Angew. Chem. Int. Ed., 2009, 48, 6354-6356.

22 N. Gartmann, C. Schütze, H. Ritter and D. Brühwiler, J. Phys. Chem. Lett., 2010, 1, 379-382.

23 M. Ince, N. Gartmann, C. G. Claessens, T. Torres and D. Brühwiler, Org. Lett., 2011, 13, 4918-4921.

24 Y. Y. Kievsky, B. Carey, S. Naik, N. Mangan, D. ben-Avraham and I. Sokolov, J. Chem. Phys., 2008, 128, 151102-1151102-5.

25 A. Devaux, G. Calzaferri, P. Belser, P. Cao, D. Brühwiler and A. Kunzmann, Chem. Mater., 2014, 26, 6878-6885.

26 D. Brühwiler, G. Calzaferri, T. Torres, J. H. Ramm, N. Gartmann, L.-Q. Dieu, I. Lopez-Duarte and M. V. Martinez-Diaz, J. Mater. Chem., 2009, 19, 8040-8067. 
H. Yang, N. Coombs and G. A. Ozin, Nature, 1997, 386, 692-695.

P. Cao, H. Li, P. Zhang and G. Calzaferri, Langmuir, 2011, 27, 12614-12620.

P. Cao, Y. Wang, H. Li and X. Yu, J. Mater. Chem., 2011, 21, 2709-2714.

N. S. Kehr, A. Schäfer, B. J. Ravoo and L. De Cola, Nanoscale, 2010, 2, 601-605.

Y. Wang, H. Li, Y. Feng, H. Zhang, G. Calzaferri and T. Ren, Angew. Chem. Int. Ed., 2010, 49, 1434-1438.

S. Hashimoto, K. Samata, T. Shoji, N. Taira, T. Tomita and S. Matsuo, Microporous Mesoporous Mater., 2009, 117, 220-227.

A. Zabala Ruiz, H. Li and G. Calzaferri, Angew. Chem. Int. Ed., 2006, 45, 5282-5287.

A. Zabala Ruiz, D. Brühwiler, T. Ban and G. Calzaferri, Monatsh. Chem., 2005, 136, 77-89.

A. I. Lupulescu, M. Kumar and J. D. Rimer, J. Am. Chem. Soc., 2013, 135, 6608-6617.

I. Lopez-Duarte, L.-Q. Dieu, I. Dolamic, M. V. Martinez-Diaz, T. Torres, G. Calzaferri and D. Brühwiler, Chem. Eur. J., $2011,17,1855-1862$.

7 L.-Q. Dieu, A. Devaux, I. Lopez-Duarte, M. V. Martinez-Diaz, D. Brühwiler, G. Calzaferri and T. Torres, Chem. Commun., 2008, 1187-1189.

T. Ban, D. Brühwiler and G. Calzaferri, J. Phys. Chem. B, 2004, 108, 16348-16352.

H. Maas and G. Calzaferri, Angew. Chem. Int. Ed., 2002, 41, 2284-2288.

J. Landers, G. Y. Gor and A. V. Neimark, Colloid. Surf. A: Physicochem. Eng. Aspects, 2013, 437, 3-32.

M. Kruk, M. Jaroniec, R. Ryoo and J. M. Kim, Microporous Mater., 1997, 12, 93-106.

P. I. Ravikovitch and A. V. Neimark, Colloid. Surf. A: Physicochem. Eng. Aspects, 2001, 187-188, 11-21.

L. K. Patterson and E. Vieil, J. Phys. Chem., 1973, 77, 1191-1192.

J. W. Larsen and L. J. Magid, J. Am. Chem. Soc., 1974, 96, 5774-5782.

H.-P. Lin, C.-P. Kao, C.-Y. Mou and S.-B. Liu, J. Phys. Chem. B, 2000, 104, 7885-7894.

P. I. Ravikovitch, S. C. Ó Domhnaill, A. V. Neimark, F. Schüth and K. K. Unger, Langmuir, 1995, 11, 4765-4772.

S. V. Koroleva and A. I. Victorov, Phys. Chem. Chem. Phys., 2014, 16, 17422-17425.

S. Ikeda, S. Hayashi and T. Imae, J. Phys. Chem., 1981, 85, 106-112.

J. S. Beck, J. C. Vartuli, W. J. Roth, M. E. Leonowicz, C. T. Kresge, K. D. Schmitt, C. T.-W. Chu, D. H. Olson, E. W. Sheppard, S. B. McCullen, J. B. Higgins and J. L. Schlenker, J. Am. Chem. Soc., 1992, 114, 10834-10843.

M. Kruk, M. Jaroniec and A. Sayari, J. Phys. Chem. B, 1997, 101, 583-589.

1 V. Urbanova and A. Walcarius, Z. Anorg. Allg. Chem., 2014, 640, 537-546. 